\title{
Characterization of Colorectal Cancer Development in $\mathrm{Apc}^{\mathrm{min} /+}$ Mice
}

\author{
ILKe Nalbantoglu, Valerie Blanc, and Nicholas O. Davidson
}

\begin{abstract}
The $\mathrm{Apc}^{\mathrm{min} /+}$ mouse provides an excellent experimental model for studying genetic, environmental, and therapeutic aspects of intestinal neoplasia in humans. In this chapter, we will describe techniques for studying colon cancer development in $A p c^{\mathrm{min} /+}$ mice on C57BL/6J (B6) background, focusing on the roles of environmental modifiers, including Dextran Sulfate Sodium (DSS), high fat diet, and bile acid supplementation in the context of experimental colorectal cancer. This chapter also includes protocols describing extraction and purification of DSScontaminated RNA, as well as sampling, harvesting, and tissue processing. The common pathologic lesions encountered in these animals are described in detail.
\end{abstract}

\section{Keywords}

$A p c^{\min /+}$; Colorectal cancer; Adenoma; Dextran sulfate sodium; High fat; Bile acids

\section{Introduction}

Colorectal cancer (CRC) is the third most commonly diagnosed cancer as well as the third most common cause of death from cancer in the United States [1]. An estimated 132,700 men and women will be newly diagnosed with the disease and 49,700 will die from colorectal cancer in 2015 [2]. Approximately $30 \%$ of colorectal cancers have a familial or genetic component, yet less than $10 \%$ are related to well-defined syndromes [3]. In addition to genetic alterations, several environmental factors, including consumption of red meats, high fat diet, obesity, insulin resistance [4], chronic inflammation [5], and smoking [6] have been associated with a higher risk for developing sporadic colorectal cancer.

Among the pathways to colorectal cancer is the adenomacarcinoma sequence. Adenomas develop both in humans and mice as a result of chromosomal instability initiated by inactivation of APC (Adenomatous Polyposis Coli), a tumor suppressor gene located on

\footnotetext{
${ }^{2}$ In the event that they are purchased commercially, acclimate the animals to the animal facility for at least a week so that the flora and intestinal microbiome of animals are similar. Therefore, purchase mice that are 2 weeks old and keep them in the animal facility for a week or two before the experiments begin.

${ }^{3}$ Keep experimental and control groups to a minimum of $8-10$ animals to ensure statistical power. It is understood that some animals will expire during the experiment, and having a larger group will yield enough data points and samples for additional studies.

${ }^{6}$ The percentage of DSS depends on the experimental model and the additional genetic traits of the animals. Expose a small batch of animals to different percentages of DSS as an initial test run. If multiple cycles of DSS are involved in the experimental model [11], it is likely that most animals will die within the first two cycles. Depending on the mortality rate, either decreasing the DSS concentration or increasing the length of water cycle is suggested.
} 
chromosome 5q [7] and which is mutated in the overwhelming majority of sporadic CRC [8]. The APC gene is an essential component of $\beta$-catenin and Wnt signaling pathways, regulating cell adhesion, differentiation, polarity, migration, and apoptosis [7]. Germline APC mutations cause FAP (Familial Adenomatosis Polyposis), making this an important target to study the genetic and environmental modifiers of CRC.

The laboratory mouse has proven useful in the study of CRC [9]. The Min (Multiple intestinal neoplasia) mutant arose following treatment of mice with ethylnitrosourea (ENU) [10]. Crossing ENU-treated mice with wild-type controls yielded offspring with the min phenotype. $A p c^{m i n / t}$ is an autosomal dominant allele characterized by development of multiple intestinal tumors and anemia [11]. Ap $c^{\mathrm{min} / t}$ mice in the C57BL/6J (B6) genetic background develop more than 50 tumors by 90 days of age, mostly throughout the small intestine, and although these tumors rarely become invasive, they cause death around 150 days of age as a result of intestinal obstruction and anemia due to bleeding from the larger polyps [11]. Other models, including conditional APC mutant alleles, have also been described [12].

$A p c^{m i n / t}$ mice share many genetic and phenotypic similarities to humans with FAP. The mouse and human APC orthologs are approximately $90 \%$ identical [13], but colonic tumors are more common and have much greater malignant potential in humans, whereas small intestinal tumors are more prevalent in mice [13]. Unlike the human phenotype, desmoid tumors and epidermoid cysts are rarely observed in the mouse model [13].

The $A p c^{m i n /+}$ mouse provides an excellent experimental model for studying genetic, environmental, and therapeutic aspects of intestinal neoplasia in humans. In this chapter, we will describe techniques for studying colon cancer development in $\mathrm{Apc}^{\mathrm{min} /+}$ mice on a C57BL/6J (B6) genetic background, focusing on Dextran Sulfate Sodium-induced (DSS) [14-17], high fat diet-induced [18-20], and bile acid supplementation [21, 22] as environmentally modifiable models of colorectal cancer. This chapter also includes protocols describing extraction and purification of DSS-contaminated RNA [23], as well as sampling, harvesting, and tissue processing. The common pathologic lesions encountered in these animals are described in detail.

\section{Materials}

\subsection{Dextran Sulfate Sodium Model of Colorectal Cancer in $\mathrm{Apc}^{\mathrm{min} /+}$ Mice}

1. $A p c^{\mathrm{min} /+}$ mice, 4 weeks old, commercially purchased from Jackson Laboratories (Bar Harbor, ME) (see Notes 1_4 $)$.

2. Dextran Sulfate Sodium (DSS), molecular weight of 40,000 (Affymetrix): $2-2.5 \%(\mathrm{w} / \mathrm{w})$ solution in water.

3. Teklad Mouse Breeder diet, $10.5 \%$ fat.

\footnotetext{
${ }^{1}$ If the animals are going to be bred in house, maintain the $A p c^{m i n /+}$ mice as heterozygous breeding pairs. Homozygosity for this gene is lethal.

${ }^{4}$ Conduct experiments on both genders of mice to eliminate possible gender selection/susceptibility. In our experience, there is no gender effect in adenoma or carcinoma incidence.
} 
4. Ketamine/Xylazine cocktail: $100 \mu \mathrm{l} / 10 \mathrm{~kg}$ solution containing $8 \mathrm{mg} / \mathrm{ml}$ ketamine and $3 \mathrm{mg} / \mathrm{ml}$ Xylazine.

5. Insulin syringe, $1 \mathrm{ml}$.

6. Scale, $0.1(\mathrm{~g})$ digits.

7. BrdU solution: $18 \mathrm{mg} / \mathrm{ml} \mathrm{BrdU}$ and $1.8 \mathrm{mg} / \mathrm{ml} 5$ Fluoro-2deoxyuridine in deionized water.

\subsection{High Fat Diet and Colorectal Cancer in Apc ${ }^{\mathrm{min} /+}$ Mice}

1. High fat diet, $20.5 \%$ protein, $36 \%$ fat, and $35.7 \%$ carbohydrate.

2. Contour TS Glucometer.

3. Heat lamp.

4. Rodent restrainer.

5. Scalpel blade.

6. Alcohol swap.

7. Insulin Syringe.

8. Heparin.

\subsection{Bile Acids and Colorectal Cancer in Apc ${ }^{\mathrm{min} /+}$ Mice}

1. Sodium deoxycholate ( $\geq 97 \%$ titration): $0.2 \%(\mathrm{w} / \mathrm{v})$ solution in drinking water.

\subsection{Tissue Collection and Processing}

1.

2.

3

4. Square dish with grid (ten dishes per bag).

5. Ethanol, $70 \%$.

6. Scalpel blade Scissors (5 in. surgical scissors).

7. $\quad$ Razor blade.

8. Pins.

9. Formalin solution, $10 \%$ buffered.

10. Fisherbrand, Tru-Flow tissue cassette.

11. Solvent resistant cassette marking pen.

12. Eppendorf tubes $(1.7 \mathrm{ml})$. 
13. Liquid nitrogen.

14. Nikon Stereomicroscope.

15. MetaVue software (Molecular Devices).

16. Photometrics CooLSNAP camera (ROPER Scientific).

\subsection{Magnetic Bead-Based Poly-A Purification of DSS-Exposed mRNA}

1. Tissue homogenizer.

2. Trizol Reagent.

3. UV spectrophotometry or Agilent 2100 Bioanalyzer.

4. Dynabeads mRNA purification kit (Invitrogen, Life Technology).

5. Magnet Dynal:DynalMPC-S.

6. High Capacity Reverse Transcription Kit (Applied Biosystems).

7. Binding Buffer: $20 \mathrm{mM}$ Tris-HCI pH 7.5, $1 \mathrm{M} \mathrm{LiCI}$, and 2 mM EDTA.

8. Washing buffer: $10 \mathrm{mM}$ Tris-HCI $\mathrm{pH} 7.5,0.15 \mathrm{M} \mathrm{LiCI}$, and $1 \mathrm{mM}$ EDTA.

\subsection{Protein Extract Preparation}

1. Tissue lysis buffer (TLB): $20 \mathrm{mM}$ Tris $\mathrm{pH} 7.5,1 \mathrm{mM}$ sodium vanadate, $150 \mathrm{mM} \mathrm{NaCl}, 2 \mathrm{mM}$ EDTA, $100 \mathrm{mM}$ sodium fluoride, $50 \mathrm{mM}$ betaglycerophosphate, $5 \%$ glycerol, protease inhibitors cocktail.

2. Detergent buffer (10x): $10 \%$ Triton X-100, $1 \%$ Sodium Dodecyl Sulfate in tissue lysis buffer.

\section{Methods}

\subsection{Dextran Sulfate Sodium Model of Colorectal Cancer in Apc ${ }^{\mathrm{min} /+}$ Mice}

1. House 4-week-old $A p c^{\mathrm{min} /+}$ mice (male and female) in groups and maintain on a $12 \mathrm{~h}$ light/dark cycle (see Notes $1 \_4$ ).

2. Feed mice with Teklad Mouse Breeder diet ad libitum.

3. Weigh all animals before the start of DSS exposure.

4. $\quad$ Expose mice (experimental group-4 week old) to 2-2.5\% DSS in drinking water for 1 week ( see $^{\text {Notes } 5 \_7}$ ).

5. Follow this cycle by normal drinking water for 2 weeks.

6. Give the control group tap water ad libitum throughout the experiment.

\footnotetext{
${ }^{5}$ Use the same batch of DSS (record lot number) throughout all experiments when possible as the potency of DSS may vary lot to lot. ${ }^{7}$ Induction of neoplasia in animals can be accelerated by injection of azoxymethane $(10 \mathrm{mg} / \mathrm{kg} / \mathrm{kg}$ body weight administered by intraperitoneal injection at 8 weeks of age) [15].
} 
7. Weigh animals twice a week. If multiple cycles of DSS are being administered, taking weight measurements once a week during consecutive water and DSS cycles is sufficient.

8. Record the mortality rate and the weight of the animals throughout the experiment.

9. Sacrifice animals with weight loss of $20 \%$ or more by injecting $100 \mu \mathrm{l} / 10$ $\mathrm{kg}$ of a Ketamine/Xylazine solution, followed by cervical dislocation (see Note 8).

10. Euthanize all other surviving animals at weeks $2,3,4$, and ultimately 5 to follow the progression of the pathology.

11. Two hours before sacrification, inject $200 \mu \mathrm{l}$ of BrdU solution (a marker of proliferation) per mouse.

12. Perform gross examination, imaging of the intestines including assessment of tumor number and size and tissue collection following sacrifice (see Subheading 4).

\subsection{High Fat Diet and Colorectal Cancer in $\mathrm{Apc}^{\mathrm{min} /+}$}

1.

House 4-week-old $A p c^{\min /+}$ mice (male and female) in groups and maintain on a $12 \mathrm{~h}$ light/dark cycle (see Notes $1 \_4$ ).

2. Give regular tap water ad libitum.

3. Give the experimental group a high fat diet for 8 weeks ad libitum (see Note 9).

4. Give the control group Teklad breeder diet ad libitum.

5. Weigh both the experimental and control group animals weekly ( see Note $\left.{ }^{10}\right)$.

6. Collect blood samples from tail following $5 \mathrm{~h}$ fasting at 8 and 12 weeks of age for glucose concentrations ( see Note 11).

7. At week 12, sacrifice all animals by injecting $100 \mu \mathrm{l} / 10 \mathrm{~kg}$ of a Ketamine/ Xylazine cocktail solution followed by cervical dislocation ( see $^{\text {Note } 8}$ ).

8.

At the time of sacrifice, obtain approximately $200-300 \mu$ blood from inferior vena cava using a $1 \mathrm{ml}$ heparinized syringe ( see $^{\text {Note } 12}$ ). Collect

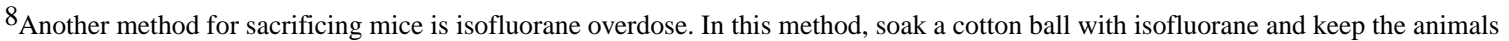
in a closed chamber until they expire. Cervical dislocation can also be carried out after isofluorane anesthesia is established.

${ }^{9}$ There are several commercially available high fat diet regimens. Adjusted calories diet (60\% saturated fatty acid, milk fat and butter fat, sucrose $34 \%$ per weight and cholesterol $0.2 \%$, Harlan Teklad) is most commonly used in our laboratory.

10 If necessary, body composition can be measured at 4-, 8-, and 12-week endpoints by DEXA scan under isofluorane anesthesia. ${ }^{11}$ Expose the animals to a heating lamp for $10 \mathrm{~min}$. This will cause vascular congestion and the tail blood sampling will be much easier. Place the animal in a mouse restrainer, make a small nick at the $1 / 3$ distal end of the tail at 12 o'clock position where the vessel is visible on the dorsal site. Clean with alcohol and make a small cut with the blade. Other methods for collecting blood are retroorbital approach and cardiac puncture.
} 
plasma by centrifugation $\left(1500 \times g\right.$ for $10 \mathrm{~min}$ at $\left.4{ }^{\circ} \mathrm{C}\right)$ and store at $-80{ }^{\circ} \mathrm{C}$ (Optional).

9. Collect and weigh mesenteric, retroperitoneal, and epididymal fat pads.

10. Perform lipidomic profiling on the intestinal mucosa (optional) [24].

11. Perform gross examination, imaging of the intestines including assessment of tumor number and size and tissue collection following sacrifice (see Subheading 4).

\subsection{Bile Acids and Colorectal Cancer in APCmin/+ Mice}

1. House 4-week-old $A p c^{\mathrm{min} /+}$ mice (male and female) and maintain on a 12 h light/dark cycle ( see $^{\text {Notes } 1 \_4}$ ).

2. Feed mice with Teklad Mouse Breeder diet ad libitum.

3. Weigh all animals before the start of the experiment.

4. Give $0.2 \%$ sodium deoxycholate in drinking water to experimental group for 12 weeks ad libitum.

5. Give regular tap water to the control group ad libitum.

6. Monitor both the control and experimental groups daily and weigh them weekly.

7. Measure fecal bile acid output from stool (collected for $72 \mathrm{~h}$ from individually housed mouse) [15] if desired. This step is optional.

8. At week 16, sacrifice all animals by injecting $100 \mu \mathrm{l} / 10 \mathrm{~kg}$ of a Ketamine/ Xylazine solution, followed by cervical dislocation ( see Note 8 ).

9. Determine bile acid pool size from total content of small intestine, gallbladder, and liver following sacrifice (optional) if desired [15].

10. Perform gross examination, imaging of the intestines including assessment of tumor number and size and tissue collection following sacrifice (see Subheading 4).

\subsection{Tissue Collection and Processing}

\subsubsection{Preparation of $2 \%$ Agar}

1. Melt $1 \mathrm{~g}$ of agar in $50 \mathrm{ml}$ of water in microwave.

2. Place the flask containing agar in a Becker containing $\mathrm{H}_{2} \mathrm{O}$ maintained at $55^{\circ} \mathrm{C}$.

At this temperature, agar remains liquid but is not too hot and won't damage tissue.

\footnotetext{
12 The heparinized syringes are commercially available and are more standardized. Another way to make a heparinized syringe is to wash a regular syringe with heparin. Pull a small amount of heparin into the injector and "wash" the barrel of the injector by moving the plunger back and forth a few times.
} 


\subsubsection{Preparation of Wax Boards}

1.

2.

3.

\subsubsection{Tissue Collection and Image Analysis}

1. Euthanize animals by Ketamine/Xylazine injection followed by cervical dislocation.

2. Swab the abdominal skin with alcohol and open the abdominal cavity with scissors using caution not to lacerate abdominal organs.

3. Dissect the spleen, located right under the stomach, from the surrounding adipose tissue and viscera with scissors. Record the dimensions and weight.

4. Place the tissue in an Eppendorf tube and snap freeze in liquid nitrogen.

5. $\quad$ Expose and dissect the small and large intestines.

6. Remove and discard the cecum, which is a small saccular structure between small and large intestine (see Note 15$)$.

7. Separate small intestine from colon.

8. Measure and record the length of large and small intestine with a ruler.

9. Dissect off the mesenteric adipose tissue and attached vessels from the small and large intestines.

10. Cut small intestine in three equal sections (proximal, mid, distal). Depending on the size of the wax plate, further cut proximal, mid, and distal sections of small intestine into two equal pieces. Colon usually remains as a single piece, but can be cut into two equal pieces to fit on the wax plate.

11. Flush each segment with cold PBS, open longitudinally and pin down on a wax plate (Fig. 1 and see Note 16).

\footnotetext{
13 Melting the Penwax may take up to several hours. Dishes come in bag of ten and one case contains ten bags. One pound of wax is sufficient to prepare ten wax plates. One plate can be used several times. These can be kept at room temperature and can be melted and poured again if needed.

${ }^{14}$ Keep at least one or two wax boards free of formalin contamination. This is necessary for gross examination/imaging and dissection of normal and tumor tissues that will be processed for protein and RNA extraction.

${ }^{15}$ This step is optional. Cecum is a small sac-like structure at the intersection of small and large intestine. It is difficult to orient and pin on a wax plate. If the investigators would like to include this for histologic examination, marking it with tissue dyes is recommended, since it is histologically identical to the rest of the colon.

${ }^{16}$ Use ten pins per intestinal section. Approximately 70 pins are used per animal. These pins are re-usable. Keep a set of pins free of formalin contamination.
} 
12. Perform the gross imaging using a Nikon SMZ800 microscope and photograph the tissues using a Photometrics CooLSNAP camera.

13. Place the intestines in $10 \%$ formalin, enough to cover and submerge the tissue completely (1:10 ratio of tissue and formalin solution). Fix overnight at room temperature.

14. Rinse the intestines with PBS and keep in PBS at $4{ }^{\circ} \mathrm{C}$ until embedding (see Note 17 ).

15. Use MetaVue software for width, length, and total area measurements.

16. Before starting further dissection, make sure that all the materials are ready and are located within reach for further tissue sectioning and preparation (Fig. 2a). This will streamline the process and prevent tissue from drying.

17. Cut each pinned tissue segment into pieces approximately $2 \mathrm{~cm}$ in length $\left(\right.$ see $\left.^{\text {Note } 18}\right)$.

18. Cut each segment longitudinally with a razor blade and separate each half (Fig. 2b, c).

19. Cover the mucosal sides of the cut sections with $55^{\circ} \mathrm{C}$ agar and set aside until the agar solidifies (Fig. 2d).

20. Cut excess agar around tissue (Fig. 2e).

21. Each $2 \mathrm{~cm}$ section results in two sister strips with mucosa facing each other (Figs. $2 \mathrm{f}$ and 3).

22. Maintain proximal-distal orientation (Fig. 3 and see Note 19).

23. While maintaining the proximal-distal orientation, align strips and cover with $55^{\circ} \mathrm{C}$ agar to form a single block (Fig. $2 \mathrm{~g}$ ).

24. Label each tissue cassette with animal type/number, experiment, and tissue type (i.e. $A p c^{m i n / t}$ DSS, small intestine) with special marker pen (see Note $20)$.

25. Once solidification is completed, place the tissue blocks into a tissue cassette (Fig. 2h).

26. Keep the cassettes in $70 \%$ Ethanol, enough to cover all the cassettes and keep at room temperature (Fig. $2 \mathrm{i}$ and see $\mathrm{Note}^{17}$ ).

\footnotetext{
17 The fixed tissue can also be stored in formalin solution.

18 A tissue cassette is approximately $2 \mathrm{~cm}$ in greatest dimension. Further section the intestines after fixation into $2 \mathrm{~cm}$ segments. This will enable the tissues to fit in the cassette and prevent tissue waste.

${ }^{19}$ Tissue dyes can be utilized to mark proximal, mid, and distal intestine. Designate and apply different color dyes to serosal surface of the intestines (i.e. red-proximal, blue-distal, mid-unstained). This way, the investigators can tell which piece belongs to which segment. Apply the tissue dyes with a cotton-tip, make sure it does not overrun between the segments. Use small amounts of dye and blot the excess with a paper towel.

${ }^{20}$ The labeling done with regular marker pens will fade during tissue processing. Therefore, use a solvent-resistant pen. Another costeffective alternative is to use a regular pencil (not a sharp writer).
} 
27. Submit the cassettes for tissue processing and hematoxylin and eosin (H\&E) staining right after the tissue is placed in the cassette, or keep longer in $70 \%$ Ethanol or formalin if submitting more than one batch.

28. Collect tissue from "lesional" and "normal" areas of colon and small intestine from separate animals within the same experimental group after the intestines are pinned on a formalin-free wax plate. Flash freeze this tissue in liquid nitrogen for RNA and protein analysis (see Subheading 3.5).

\subsection{Magnetic Bead-Based Poly-A Purification of DSS-Exposed mRNA}

This is a crucial step since any exposure of cells or tissues to DSS will severely impair the ability to extract RNA suitable for reverse transcription [23].

\subsubsection{RNA Preparation}

1. Homogenize 50-100 $\mathrm{mg}$ of harvested organs at maximum speed for $10 \mathrm{~s}$ using tissue homogenizer in $1 \mathrm{ml}$ of Trizol agent.

2. Extract RNA in Trizol following Manufacturer's protocol. Five to ten microgram of total RNA will be used for binding to Dynabeads.

3. Adjust the volume of RNA to $100 \mu \mathrm{l}$ with $\mathrm{H}_{2} \mathrm{O}$, heat the solution to $65^{\circ} \mathrm{C}$ for 2 min to disrupt secondary structures.

4. Place the RNA solution on ice.

3.5.2 Preparation of Dynabeads-All the following steps are performed at room temperature.

1. Transfer $50 \mu \mathrm{l}$ of beads to a $1.7 \mathrm{ml}$ microcentrifuge tube.

2. Place the tube on the Magnet Dynal for $30 \mathrm{~s}$.

3. Pipette off the supernatant, remove the tube from the magnet, and add 100 $\mu \mathrm{l}$ of Binding Buffer to equilibrate the beads.

4. Place the tube back to the magnet and remove the supernatant.

5. Remove the tube from the magnet and add $100 \mu \mathrm{l}$ of Binding Buffer (see Note 21 ).

3.5.3 mRNA Purification-All the following steps are performed at room temperature.

1.

Add the total RNA (100 $\mu$ l) (Subheading 3.5, step 5) to the Dynabeads/ Binding Buffer suspension.

2. Mix thoroughly manually until all the beads are re-suspended and rotate the tube on a wheel 3-5 min at room temperature to allow binding of the RNA to the oligo(dT) beads.

\footnotetext{
${ }^{21}$ Obtain optimal hybridization conditions in Binding Buffer by adding in a 1:1 ratio relative to sample volume.
} 
3. Place the tube on the magnet until the solution is cleared within seconds and remove supernatant.

4. Remove the tube from the magnet and wash the mRNA-beads complex twice with $200 \mu \mathrm{l}$ Washing Buffer.

5. Remove the supernatant between each wash by placing the tube back on the magnet.

6. Elute the RNA with $20 \mu \mathrm{l}$ of $10 \mathrm{mM}$ Tris- $\mathrm{HCl} \mathrm{pH}$ 7.5.

7. Heat the tube to $65-80{ }^{\circ} \mathrm{C}$ for $2 \mathrm{~min}$ and place it immediately on the magnet.

8. Transfer the eluted RNA to a new Eppendorf tube in ice.

\subsection{4 cDNA Synthesis}

1. Use the eluted RNA directly in the cDNA reaction carry out using the Applied Biosystems High Capacity Reverse transcription kit.

2. Thaw $10 \times$ Reverse Transcriptase (RT) buffer, $10 \times$ random primers and $25 \times$ dNTPs on ice to preserve reagents stability.

3. Prepare Master Mix on ice as follows: per reaction $(10 \mu \mathrm{l}): 2 \mu \mathrm{l} 10 \times \mathrm{RT}$ buffer, $0.8 \mu \mathrm{l} 25 \times$ dNTPs, $2 \mu \mathrm{l} 10 \times$ Random primers, $1 \mu \mathrm{l}$ MultiScribe Reverse transcriptase, $4.2 \mu \mathrm{H}_{2} \mathrm{O}$.

4. Combine, RNA $(\sim 1 \mu \mathrm{g})$ with $10 \mu \mathrm{l}$ Master Mix in thin-walled PCR tube and complete to $20 \mu \mathrm{l}$ with autoclaved $\mathrm{H}_{2} \mathrm{O}$ ( see $^{\text {Note 22}}$ ).

5. Perform the reaction as follows: $10 \mathrm{~min}$ at $25^{\circ} \mathrm{C}, 120 \mathrm{~min}$ at $37^{\circ} \mathrm{C}, 5 \mathrm{~s}$ at $85{ }^{\circ} \mathrm{C}$.

6. Keep cDNAs at $-80{ }^{\circ} \mathrm{C}$ until further used for analysis of RNA expression by PCR [24].

\subsubsection{Protein Extract Preparation}

1. Homogenize $100 \mathrm{mg}$ of tissue in $600 \mu \mathrm{l}$ of tissue lysis buffer for $10 \mathrm{~s}$.

2. Place the homogenate in an Eppendorf tube and keep in ice.

3. Add $1 / 10$ of the volume of $10 \times$ detergent to the homogenate.

4. Vortex for $20 \mathrm{~s}$ and keep on ice for $15 \mathrm{~min}$.

5. Centrifuge the homogenate at maximum speed $(18,000 \times g)$ at $4{ }^{\circ} \mathrm{C}$ for 15 min in tabletop Eppendorf centrifuge.

6. Transfer the supernatant into a new Eppendorf tube and keep at $-80{ }^{\circ} \mathrm{C}$ until further analysis by Western Blot.

\footnotetext{
${ }^{22}$ As little as $0.2 \mu \mathrm{g}$ of RNA can be used in the reverse transcription reaction.
} 


\subsection{Assessment of Histology and Immunohistochemistry \\ 3.6.1 Hematoxylin \& Eosin Assessment of Normal Mucosa and Common Pathologic Lesions}

1.

Hematoxylin and Eosin (H\&E) staining is the standard method for evaluating the morphology of tissues. Make sure that the reviewer is blinded to the experimental and control groups. The normal wall structures from mucosa to serosa (serosal side towards exterior) as well as pathologic changes can be easily identified in well-oriented sections. If the sections are not oriented correctly, it may cause errors in histopathologic examination and lesions may be missed. All figures provided in this chapter represent well-oriented sections.

2. Identify wall structures and cellular components of small (Fig. $4 \mathrm{a}$ and see Note 23 ) and large intestine (Fig. $4 \mathrm{~b}$ and see ${ }^{\text {Note } 24}$ ). This will help recognize any pathologic lesions that may occur.

3. Identify and count the adenomas in both small and large intestine including single crypt adenomas (Figs. 5a, b, 6a and see Note 25). Remember that single crypt adenomas are small and are not visible by gross examination.

4. Identify and count the adenomas with high-grade dysplasia in both small and large intestine (Fig. 6 b and see Note 26).

5. Identify and count intramucosal (not shown) and invasive carcinomas (Fig. 6c). Note the depth of invasion for invasive tumors $\left(\operatorname{see}^{\text {Note } 27}\right)$.

\footnotetext{
${ }^{23}$ The wall of the small intestine in mouse is identical to humans and is composed of mucosa, muscularis mucosae, submucosa, muscularis interna, muscularis externa, and serosa [25] (Fig. 4a). It is important to recognize and document all the components of normal small intestinal mucosa, which is mainly composed of crypts lined by Goblet, absorptive, Paneth, and endocrine cells forming villiform structures protruding into the lumen. Lamina propria is the space between crypts that has minimal inflammation but contains vessels and lymphatics supported by a connective tissue (Fig. 4a). Muscularis mucosae is a thin layer of smooth muscle that separates mucosa from submucosa. Muscularis mucosae can be difficult to recognize in poorly oriented sections (not shown in Fig. 4a). The submucosa is the small space between muscularis mucosae and muscularis interna; it contains blood vessels and lymphoid aggregates (Peyer's patches). Lymphoid aggregates can sometimes extend into the mucosa. In contrast to human bowel, submucosa is not wellvisualized in mouse intestine. Muscularis interna and externa are thicker bundles of muscle and have ganglion cells and nerve bundles in between (Fig. 4a). These (muscularis interna and externa) correspond to the muscularis propria in humans. Serosa is the most outer layer, mostly lined by peritoneum.

${ }^{24}$ In contrast to small intestine that has villi, the colonic (large intestine) mucosa is flat and does not have villi. In proximal mouse colon mucosal folds are most commonly seen as horizontal ridges. The colonic mucosa is composed of crypts lined by Goblet cells, enterocytes, and rare endocrine cells. Lamina propria has minimal to no inflammation (Fig. 4b). Scattered lymphoid aggregates can be seen. The remainder of the wall components in colon is identical to small intestine, but muscularis mucosae is very poorly formed and not well-visualized in most cases (Fig. 4b) [25].

${ }^{25}$ The histologic lesions in the $A p c^{\text {min } /+}$ mouse closely mimic the FAP lesions in humans $[13,26]$. The morphologic spectrum of the intestinal lesions that can be seen in $A p c^{\mathrm{min} / t}$ mice varies from adenoma to invasive carcinoma. In $A p c^{m i n / t}$ models of colorectal cancer, adenomas develop mostly in small intestine, and colonic lesions are rare. An adenoma is characterized by cigar-shaped nuclei with an increased Nucleus-Cytoplasmic ratio populating the crypts (Figs. 5a, b and 6a). Adenomas are low-grade dysplasia by definition. Adenoma and tubular adenoma terms are used interchangeably. Microadenomas, which are single crypt adenomas, can be seen in both FAP patients and $A p c^{\mathrm{min} /+}$ mice. Single crypt adenomas (Fig. 5a) will not be visible to naked eye with gross examination, whereas larger lesions will be grossly visible (Fig. 5b). Therefore, both gross and microscopic examinations of the intestines are important.

${ }^{26}$ Adenomas can be divided into low- and high-grade dysplastic lesions. High-grade lesions are characterized by architectural complexity including cribriform glandular structures, dirty luminal necrosis, and loss of nuclear polarity (Fig. 6b).

27 Intramucosal carcinomas are characterized by single cells invading into lamina propria. In contrast to colon, intramucosal carcinomas in human small intestine have a potential to metastasize to lymph nodes. Submucosal invasion is characterized by invasion of the tumor through muscularis mucosae and the presence of desmoplasia (Fig. 6c).
} 


\subsubsection{Immunohistochemistry and Assessment}

1. Obtain $4-\mu \mathrm{m}$ sections from each tissue on a charged slide (see Note 28$)$.

2. Follow the antibody staining per manufacturer's protocol. Have positive and negative controls for each immunohistochemistry run ( see Note 29$)$.

3. The evaluation of immunohistochemistry depends on the type of antibody that is used. The manufacturer's manual is the best source for staining evaluation.

4. Ki67, BrdU, and TUNEL are nuclear markers; therefore count the number of positive nuclei.

5. Evaluate intestinal proliferation by scoring full longitudinal sections of crypts and report it as number of BrdU-positive cells normalized to the total number of cells per crypt (see Fig. 7a, b).

6. Beta-catenin normally stains cytoplasmic membrane, but when mutated nuclear staining is observed (see Fig. 7c, d).

7. Evaluate the apoptotic index similarly by counting the number of TUNELpositive cells normalized to the total number of cells in crypts and villi (see Fig. 7e).

\section{Acknowledgments}

Work cited in this review was supported by the following grants: HL38180, DK56260 and Digestive Disease Research Core Center P30DK52574 to N.O.D.

\section{References}

1. American Cancer Society. Colorectal cancer facts \& figures 2014-2016. American Cancer Society; Atlanta, GA: 2014.

2. American Cancer Society. Surveillance research, 2015. American Cancer Society; Atlanta, GA: 2015.

3. Jasperson KW, Tuohy TM, Neklason DW, et al. Hereditary and familial colon cancer. Gastroenterology. 2010; 138:2044-2058. [PubMed: 20420945]

4. Chan AT, Giovannucci EL. Primary prevention of colorectal cancer. Gastroenterology. 2010; 138:2029-2043. [PubMed: 20420944]

5. Ullman TA, Itzkowitz SH. Intestinal inflammation and cancer. Gastroenterology. 2011; 140:18071816. [PubMed: 21530747]

6. Walter V, Jansen L, Hoffmeister M, et al. Smoking and survival of colorectal cancer patients: systematic review and meta-analysis. Ann Oncol. 2014; 25:1517-1525. [PubMed: 24692581]

7. Pino MS, Chung DC. The chromosomal instability pathway in colon cancer. Gastroenterology. 2010; 138:2059-2072. [PubMed: 20420946]

8. Liang J, Lin C, Hu F, et al. APC polymorphisms and the risk of colorectal neoplasia: a HuGE review and meta-analysis. Am J Epidemiol. 2013; 177:1169-1179. [PubMed: 23576677]

\footnotetext{
${ }^{28}$ Even though ideal for both $\mathrm{H} \& \mathrm{E}$ and immunohistochemistry applications, you must use charged slides for immunohistochemical staining.

${ }^{29}$ Select proper positive and negative tissue controls for each antibody run. This information is available at antibody manufacturer's website.
} 
9. Taketo MM, Edelmann W. Mouse models of colon cancer. Gastroenterology. 2009; 136:780-798. [PubMed: 19263594]

10. Moser AR, Pitot HC, Dove WF. A dominant mutation that predisposes to multiple intestinal neoplasia in the mouse. Science. 1990; 247:322-324. [PubMed: 2296722]

11. Bilger A, Shoemaker AR, Gould KA, et al. Manipulation of the mouse germline in the study of Min-induced neoplasia. Semin Cancer Biol. 1996; 7:249-260. [PubMed: 9110402]

12. Khazaie K, Zadeh M, Khan MW, et al. Abating colon cancer polyposis by Lactobacillus acidophilus deficient in lipoteichoic acid. Proc Natl Acad Sci USA. 2012; 109:10462-10467. [PubMed: 22689992]

13. Shoemaker AR, Gould KA, Luongo C, et al. Studies of neoplasia in the Min mouse. Biochim Biophys Acta. 1997; 18:F25-48.

14. Cooper HS, Everley L, Chang WC, et al. The role of mutant Apc in the development of dysplasia and cancer in the mouse model of dextran sulfate sodium-induced colitis. Gastroenterology. 2001; 121:1407-1416. [PubMed: 11729120]

15. Giammanco A, Blanc V, Montenegro G, et al. Intestinal epithelial HuR modulates distinct pathways of proliferation and apoptosis and attenuates small intestinal and colonic tumor development. Cancer Res. 2014; 74:5322-5335. [PubMed: 25085247]

16. Tanaka T, Kohno H, Suzuki R, et al. Dextran sodium sulfate strongly promotes colorectal carcinogenesis in Apc(Min/+) mice: inflammatory stimuli by dextran sodium sulfate results in development of multiple colonic neoplasms. Int J Cancer. 2006; 118:25-34. [PubMed: 16049979]

17. Xie Y, Matsumoto H, Nalbantoglu I, et al. Intestine-specific Mttp deletion increases the severity of experimental colitis and leads to greater tumor burden in a model of colitis associated cancer. PLoS One. 2013; 8:e67819. [PubMed: 23805328]

18. Baltgalvis KA, Berger FG, Pena MM, et al. The interaction of a high-fat diet and regular moderate intensity exercise on intestinal polyp development in Apc Min/+ mice. Cancer Prev Res. 2009; 2:641-649.

19. Day SD, Enos RT, McClellan JL, et al. Linking inflammation to tumorigenesis in a mouse model of high-fat-diet-enhanced colon cancer. Cytokine. 2013; 64:454-462. [PubMed: 23735174]

20. Newberry EP, Xie Y, Kennedy SM, et al. Protection against Western diet-induced obesity and hepatic steatosis in liver fatty acid-binding protein knockout mice. Hepatology. 2006; 44:11911205. [PubMed: 17058218]

21. Cao H, Luo S, Xu M, et al. The secondary bile acid, deoxycholate accelerates intestinal adenomaadenocarcinoma sequence in Apc ( $\mathrm{min} /+)$ mice through enhancing Wnt signaling. Fam Cancer. 2014; 13:563-571. [PubMed: 25106466]

22. Mahmoud NN, Dannenberg AJ, Bilinski RT, et al. Administration of an unconjugated bile acid increases duodenal tumors in a murine model of familial adenomatous polyposis. Carcinogenesis. 1999; 20:299-303. [PubMed: 10069468]

23. Kerr TA, Ciorba MA, Matsumoto H, et al. Dextran sodium sulfate inhibition of real-time polymerase chain reaction amplification: a poly-A purification solution. Inflamm Bowel Dis. 2012; 18:344-348. [PubMed: 21618356]

24. Dharmarajan S, Newberry EP, Montenegro G, et al. Liver fatty acid-binding protein (L-Fabp) modifies intestinal fatty acid composition and adenoma formation in ApcMin/+ mice. Cancer Prev Res. 2013; 6:1026-1037.

25. Atlas of Laboratory Mouse Histology. Texas histopages. 2004. http://ctrgenpath.net/static/atlas/ mousehistology

26. Preston SL, Leedham SJ, Oukrif D, et al. The development of duodenal microadenomas in FAP patients: the human correlate of the Min mouse. J Pathol. 2008; 214:294-301. [PubMed: 18085615] 


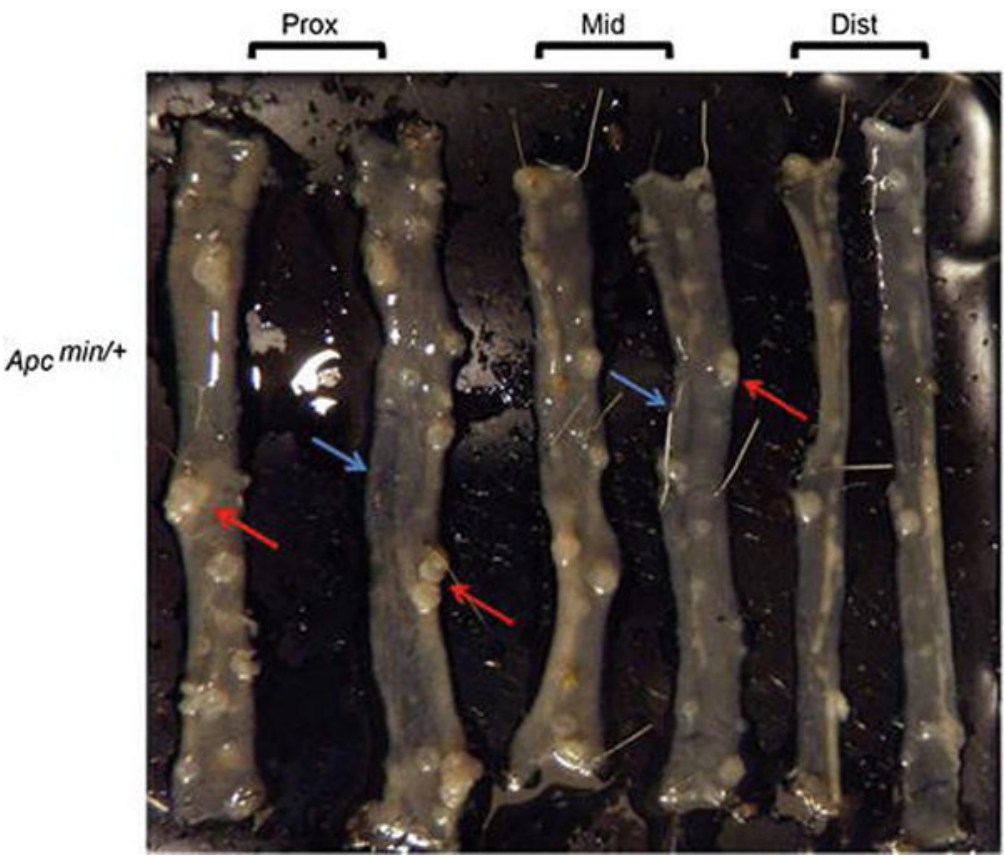

Fig. 1.

Small intestines of $A p c^{m i n / t}$ pinned on a wax board. Red arrows: intestinal polyps. Blue arrow: Grossly normal mucosa. Note grossly normal mucosa may have adenomas on microscopic examination 

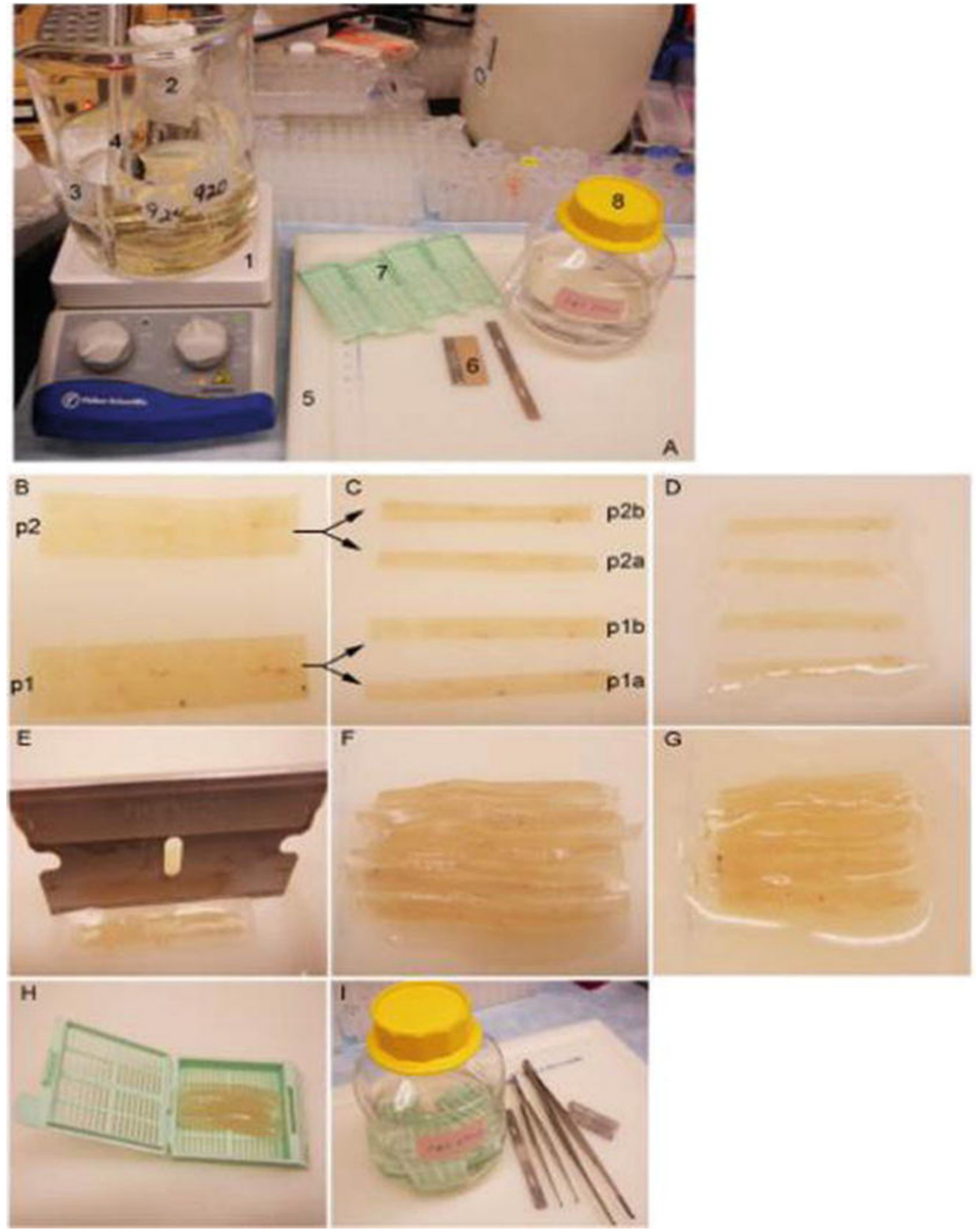

Fig. 2.

Tissue embedding process. (a) Required material. ( $($ ) heat block maintaining the agar solution at $55{ }^{\circ} \mathrm{C}$. The Becker containing the agar solution (2) is placed in a larger Becker (3) filled with water kept at $55^{\circ} \mathrm{C}$. The temperature is monitored with a thermometer (4). Cutting and embedding of tissue is done on a cutting board (5) with razor blades (6). Once processed, the embedded tissue is placed in a tissue cassette ( 7 ) and kept in $70 \%$ ethanol ( 8 ) at room temperature. Embedding process $(B-I)$. Each tissue section is cut transversally to generate a $\sim 2 \mathrm{~cm}$ long piece (b). For each section, two pieces are thus generated ( $p 1$ and $p 2$ ). 
Each fragment is then cut longitudinally into two pieces (c) (p1a, p1b, p2a, p2b). The sections are then covered with agar solution (d). Once the agar has solidified, the excess agar is removed (e). Each section is positioned as shown in Fig. 3 and covered with agar (f). Once the block has solidified and the excess agar removed (g), the tissue block is placed into a tissue cassette (h) and kept in $70 \%$ ethanol (i) 

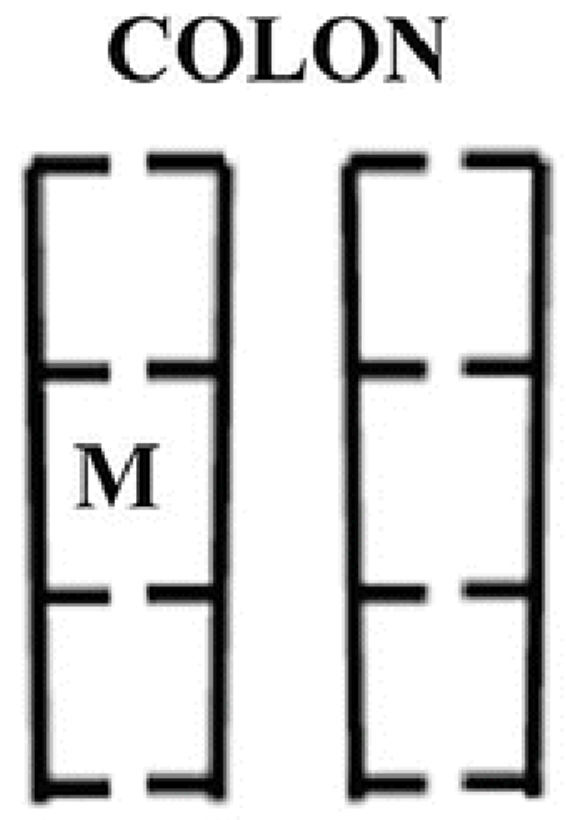

Fig. 3.

Embedding scheme for small and large intestine. $M$ mucosal side

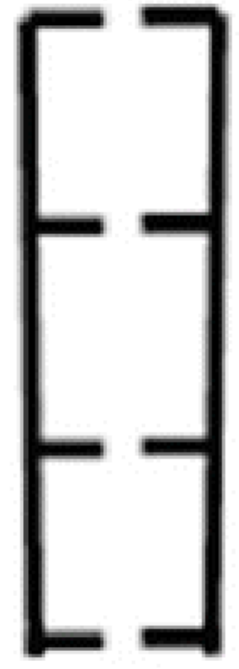

Proximal

\section{SMALL INTESTINE}
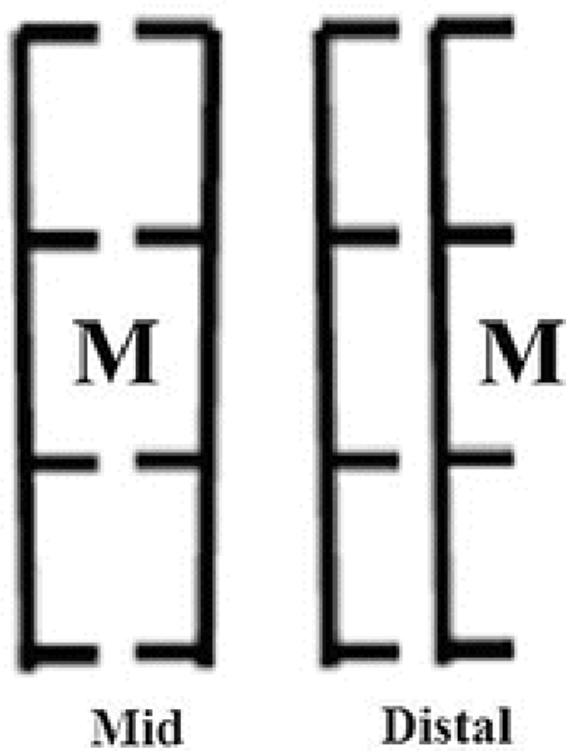

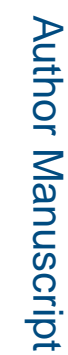

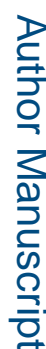

Methods Mol Biol. Author manuscript; available in PMC 2017 January 01. 


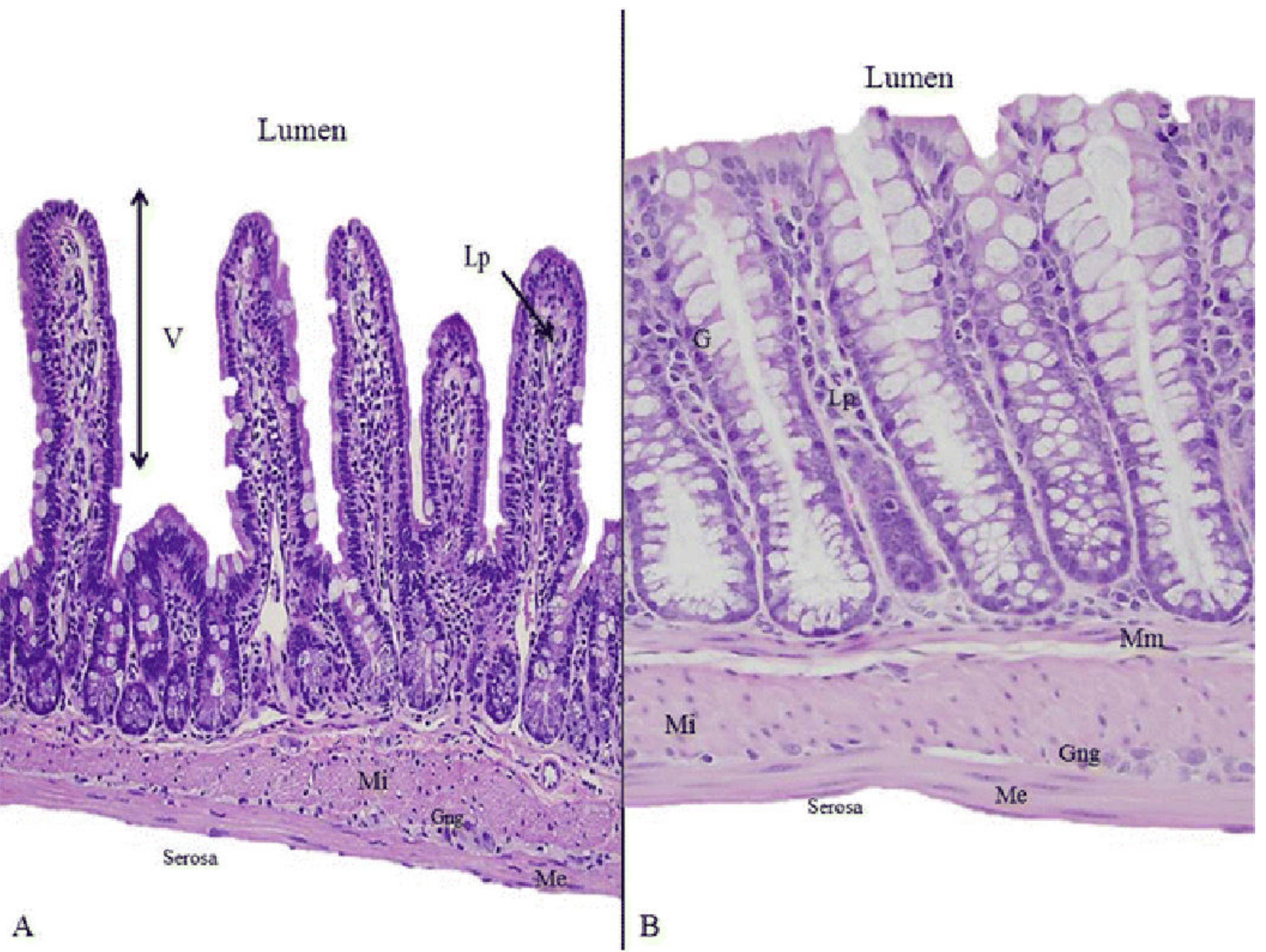

Fig. 4.

Hematoxilin and Eosin staining of normal mouse small and large intestine. Note that small intestine mucosa has villi (a, 200x), whereas colonic mucosa is flat (b, 400x). The Goblet cells lining the surface epithelium are present in both small and large intestine. Lamina propria is the space between crypts. Muscularis interna and externa are thicker bundles of muscle and have ganglion cells and nerve bundles in between the muscle layers. $V$ villus, $G$ goblet cells, $L p$ lamina propria, $M m$ muscularis mucosae, $M i$ muscularis interna, Gng Ganglion cells, Me muscularis externa 


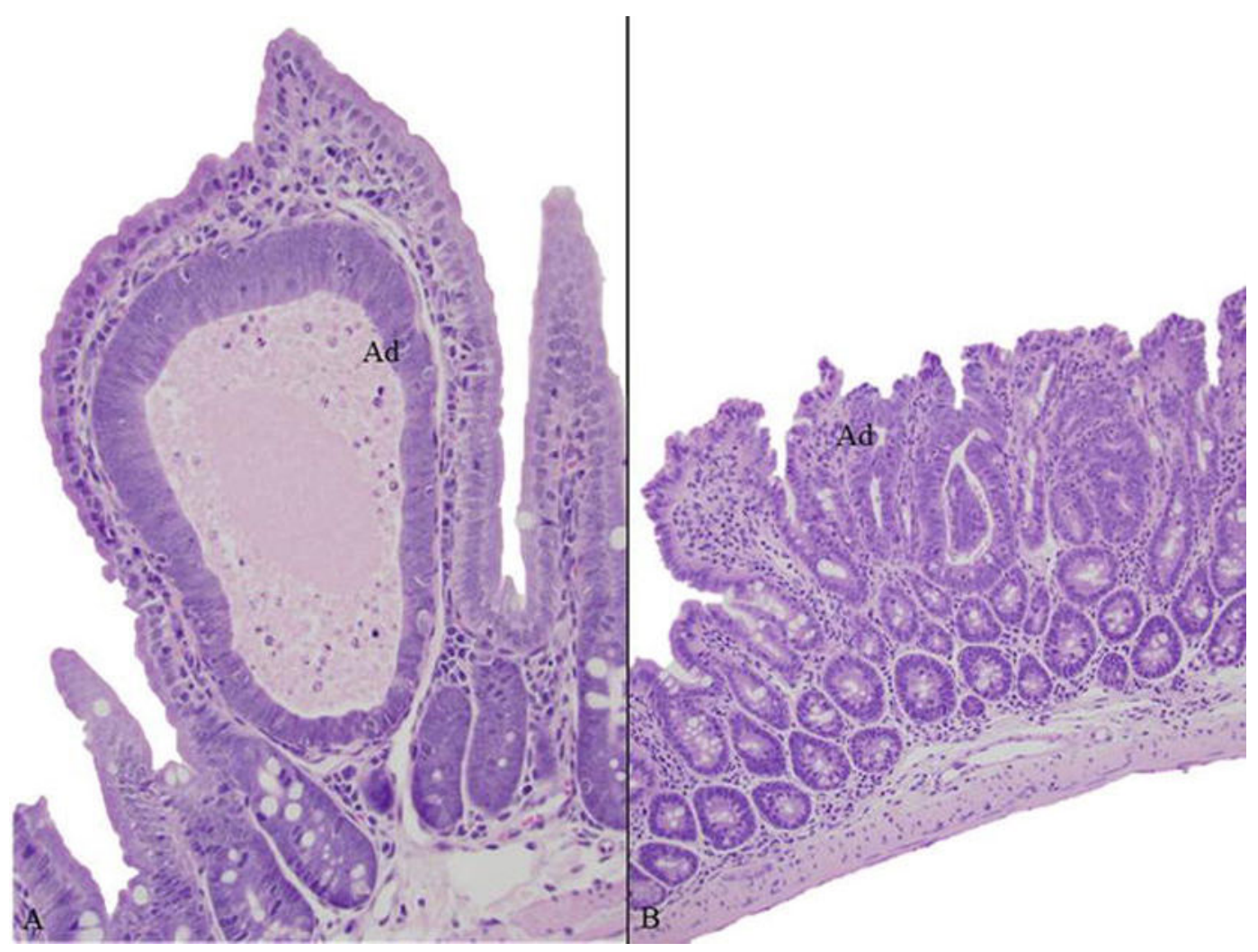

Fig. 5.

Hematoxilin and Eosin staining of single crypt adenoma and tubular adenoma in mouse small intestine. Single crypt adenomas (Ad) are commonly seen on microscopic examination (a, 400×). A classic tubular adenoma in mouse small intestine (b, 200x). Note the single dilated adenomatous gland lined with pencillate nuclei. This one gland adenoma displays classic features of an adenoma with nuclear crowding, and pseudostratification. Apoptosis can also be seen (not shown in figure). Adenomas can reach bigger sizes. Note the larger adenoma in small intestine shows similar histologic features with involvement of the surface epithelium (b) 


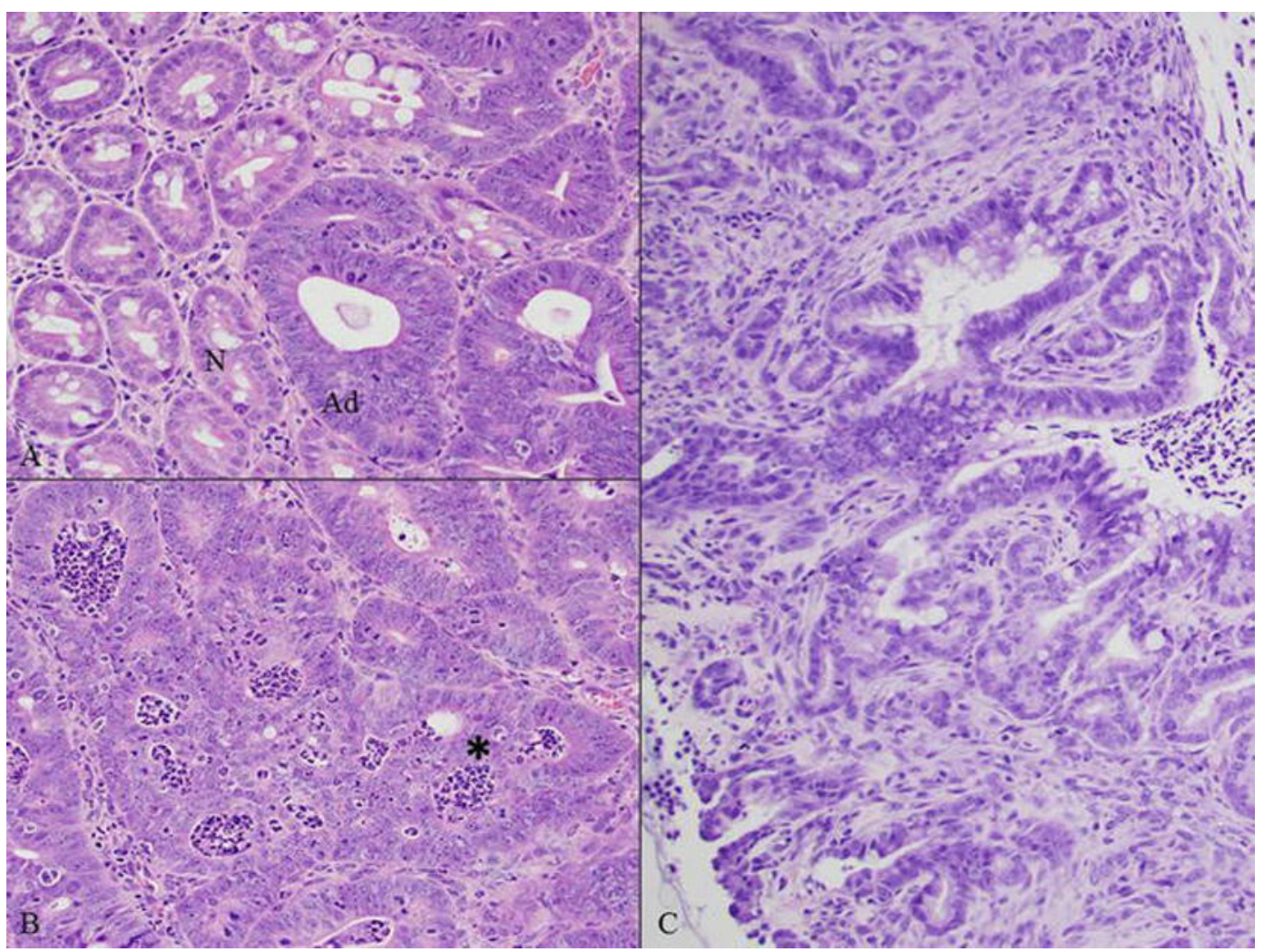

Fig. 6.

Hematoxilin and Eosin staining of adenoma in mouse small intestine, adenoma with highgrade dysplasia, and adenocarcinoma in mouse small intestine. Adenomas are low-grade dysplastic lesions (a, 400x). Note the sharp transition between normal $(\mathrm{N})$ and adenomatous crypts (Ad). Adenoma with high-grade dysplasia is characterized by cribriform glands $(*, \mathbf{b})$ and loss of nuclear polarity (b, 400×). Prominent nuclear pleomorphism and luminal necrosis $(*, \mathbf{b})$ are commonly seen. Invasive carcinomas are characterized by irregular glands and desmoplasic stroma (c, 200x) 


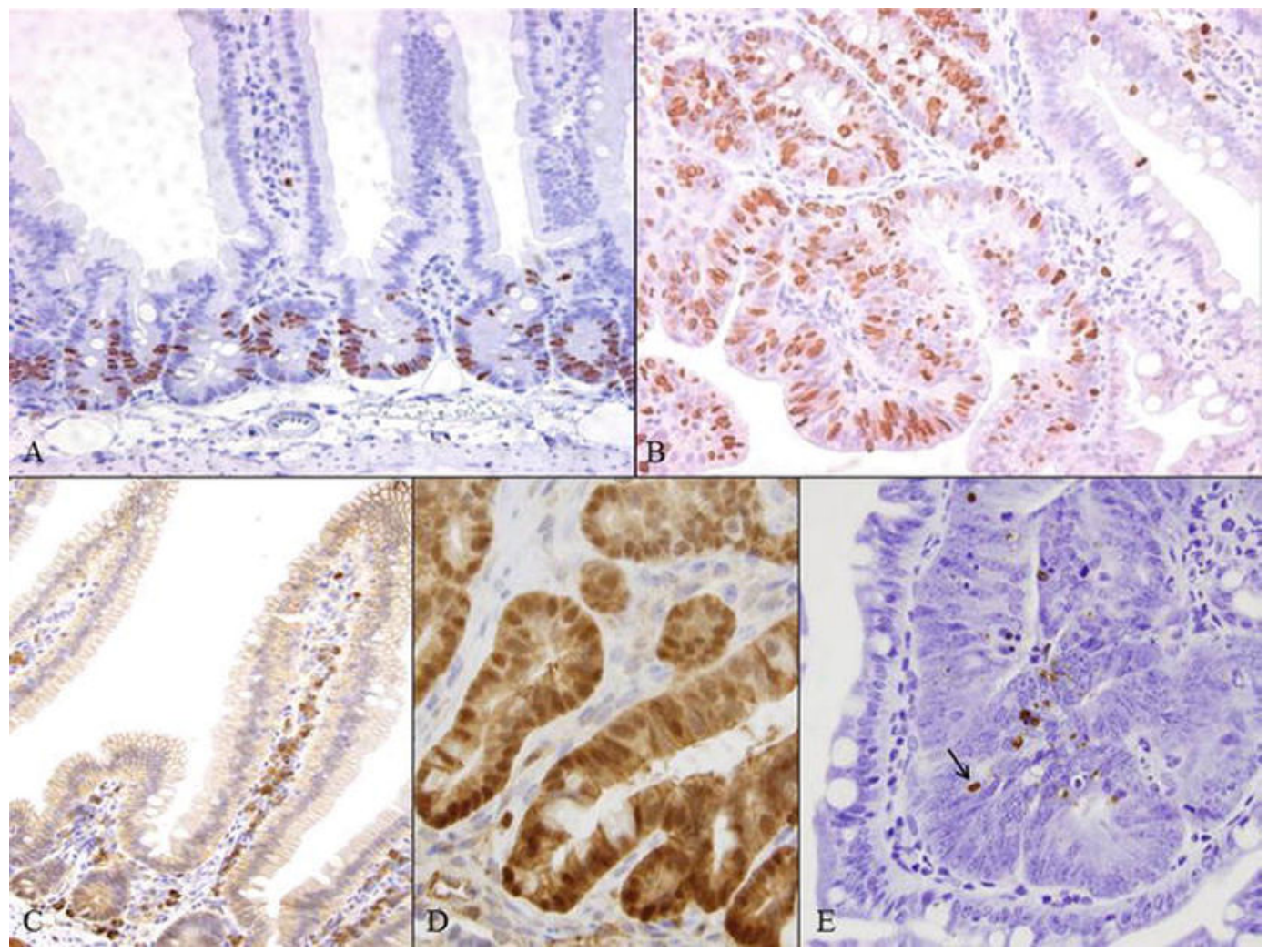

Fig. 7.

Immunohistochemical staining of BrdU, $\beta$-catenin, and TUNEL in mouse intestine. Normal BrdU staining in $A p c^{m i n / t}$ small intestine (a, 100×) and BrdU staining in $A p c^{m i n / t}$ adenoma $(\mathbf{b}, 100 \times)$. Note the positive brown colored nuclear staining. Normal $\beta$-catenin staining in mouse small intestine shows cytoplasmic membranous staining (c, $400 \times)$, whereas $\beta$-catenin mutation in an adenoma displays dense nuclear positivity $(\mathbf{d}, 600 \times)$. TUNEL staining shows positive nuclei in a small intestine adenoma (arrow, brown nuclear staining) $(\mathbf{e}, 600 \times$ ) 